\title{
The Importance of On-Going Maintenance in Preserving the Heritage Listed Buildings
}

\author{
M.A.A. Rahman, Z.A. Akasah, S.N.F. Zuraidi \\ Faculty of Civil and Environmental Engineering, Universiti Tun Hussein Onn Malaysia \\ 86400 Parit Raja, Johor, Malaysia \\ E-mail: ashrafr@uthm.edu.my
}

\begin{abstract}
Maintenance is not only important in ensuring the condition and physical of the old building to operate safely and effectively, but it also for an activity that is important in determining the life long of the building, so that it can be preserve and be inherit by the next generation. The need of maintenance is not only on repairing but more towards prevention method. According to the previous study, maintenance is done reactively; this further will cost serious problems in future. Therefore maintenance need good planning from the early stage and is followed with on-going implementation from time to time by all those who are responsible in it. In conjunction with this, this paper is to discuss about the importance of on-going maintenance in order to manage the old building after it has been gazette as heritage listed. At the end of the discussion, several strategies have been put forward in order to stimulate the practice of on-going maintenance as an initiative to encourage the culture of maintenance and also help to increase the quality process in a more effective maintenance management
\end{abstract}

Keywords - On-going Maintenance, Heritage Building, Preservation

\section{INTRODUCTION}

Malaysian has seeing the positive development when many of the old buildings had undergone the process of conservation and preservation to be reuse again. This is a success that should be appreciated by everyone in the effort of preserving and protect the national heritage asset so that it can be inherited by the next generation. Without these effort, the beautifully heritage buildings in Malaysia like Sultan Abdul Samad Building, Stadhuys Building and Kuala Lumpur Railway Station would not be seen till today.

It cannot be denied that the uniqueness and artistic found in the building has made the building valueless as compared to its' varied historical background. According to Yahya [1], the old building that can be seen till now is synonym to the historical development in a country. It has its own uniqueness in all aspect such as the architecture, history, culture and the skill in its built and emotional value that can be seen through its society [2]. Hence, it is a total loss if these buildings are left uncared without good conservation and preservation.

Dunn and Cantell [3] see the practice of conservation of the old building act as a transformation in giving the chance to the building so that it becomes a challenge to the environment. At the same time the practice of conservation will give the chance to the old building to be in this comprehensive modern community.

Nevertheless, the practice of preservation is only on temporarily basis because the art of preservation does not guarantee the life long and function of a building. The preserved building can be lasted within certain duration before it comes dilapidated. This can bring loss to all. To restore the condition, many experts agree that each and every building that has already been preserved need to be manage and maintain routinely from time to time.

According to Adi Irfan C.A. et. al. [4], maintenance is the best continuation in preservation practice. Besides concealing the physical condition, maintenance can reduce the inconvenience risk in the building operation. The practice of preservation is very costly; therefore care has to be taken in seeing the maintenance is carried out carefully so that it can give a positive feed back. Without maintenance, the effort in preservation is a failure. How efficient the preservation is, but if there is no observation and protection, the building will not functioning well to it utmost optimum.

Therefore, efforts in persevering not only focus on the practice of preservation, but it also involves the process of preservation and long term maintenance so that the building can still hang on. 


\section{Maintenance of Heritage Building: ConcePt AND TERMINOLOGIES}

Usually, the maintenance works involve the activity of repair and replace [5] but in the sense of conservation, both of this activity is not suitable to be applied. This is to protect the historical importance and keep the originality of the building from any action that may lead to unexpected destruction $[2 ; 6 ; 7]$.

According to Keromo [8], maintenance is one of the activities in conservation practice. Unlike other activity of conservation, maintenance needs to be frequently on time and not only depends on the factor of need. The concept of maintenance in conserving and preserving the built heritage is proactive and need strategic time and documentation. As a result of the proactive action and strategic documentation, thus, it can lead to continuous practice. This is justify with the meaning of maintenance of the heritage building itself that emphasis the concept of on going protection as stated in the Burra Charter, which defined maintenance from the terminology view as the continuous and protective care of the fabric and setting of a place, and is to be distinguished from repair [9].

It is clear from that definition; maintenance is not only focusing on how to improve the look of heritage building but more on the preventive and protective action on a long term basis.

\section{MaintenanCE OF HeRITAge BuILding: PRACTICE AND IMPORTANCE}

Practically, it is not easy to take care an old building. Nevertheless, it is not a reason to ignore the importance of maintenance especially in ensuring the safety of public life and their properties.

In conjunction with that, several factors have to be taken into consideration such as the longevity and sensitivity of the building as to ensure that it is error free during the building operation. In addition, the practice of maintenance should highly consider the originality and condition of the building without damaging the physical structure of the building. This action is important because the implementation of maintenance is correlated with the conservation practice and this leads to why maintenance should be practice out. One of the reasons is to enhance the value of the building and to safeguards the investment [10].

Besides that, maintenance can avoid any circumstances that lead to increase the cost in future. The originality of the structure and substance of the building are still in used therefore tendency to get the same sources for substitution is not easy. With good maintenance and substance there is no doubt the building can last longer. In another aspect, maintenance can equalize the stock of the old and the new and upcoming building. In this way, the heritage building will still be magnificent and functional even though it is surrounded by more modern buildings.

Therefore, through the stated importance of preservation, there is no way not to practice the maintenance of the heritage building.

\section{ON-GOING MAINTENANCE: A CONTINUATION APPROACH}

There is nothing more excitement in the practice of building conservation and restoration than seeing all those preserved buildings can still standing and well functional to operate like it was before. But, due to certain factor like age, vandalism, weather and building usage has made it worn but it is still off service consistently. Therefore it is important that this building is maintained all the time.

Maintaining a heritage building is nothing new. This approached has long being practiced in the early $19^{\text {th }}$ century by John Ruskin and William Morris [11]. Morris is the founder of Society for the Protection of Ancient Building (SPAB) stated "stave off decay by daily care". Based on Morris statement, maintenance on a heritage building should be done routinely from time to time. The rationale is that a work done routinely can give an effective result. Hence, in maintaining a building if it is done regularly and continuously it can give a better result.

Routine maintenance or on-going maintenance is a method of protection and observation of a heritage building from time to time. It is related to ways of preventing from any outcome or obstacle that come across during the building operation. On-going maintenance covers all important aspect that is needed by all parties that are involved in the maintenance of a heritage building including both management and technical level. In this way, it is convenient for those who involve and who are responsible to work out maintenance following their work of scope. For example, work concerning with management will be enforce by the administration level and the technical will be the technician responsibility. Combination of both aspects is important as maintenance involve the combination of several actions which includes of initiation, organization and implementation of series of work in order to retain an item or restore it to an acceptable condition [12].

Same as the periodical maintenance, the on-going maintenance involve a well planned schedule that is concerned on the control steps that predicts the upcoming break down. Based on the prediction, the fixed time rate and the continuation of maintenance can be predicted earlier and this situation will simplified the process of maintenance. Hence, the management can place fix on the maintenance according to its priority and at the same time the maintenance budget can be estimated effectively.

The old heritage buildings that stood till today have become the valuable assets to the country's development. An asset will not brings profits if the maintenance are being neglected or maintenance is only done on it if there is any serious damage or grumble from the consumers whereby this asset does not reach its optimum.

Even though, most of the building is more than 100 years but with proper observation and protection these buildings can last longer for a time of period. It is almost impossible for a building that is not maintained to last long [13].

Furthermore, on going maintenance can be seen the most suitable practice in maintaining a heritage building for its functional purpose. 


\section{On-GoIng MAINTENANCE: DeClined FACTORS}

Maintenance has be said the best steps in preserving and protecting a heritage building so that it can serve at it utmost $[3 ; 6 ; 7 ; 14]$. Even that, little has used this approached as a practice. Many have rejected this approached. According to Nigel and Dunn [3] in Rahman [15], several excuse that are belief to be the issue and dilemma has been recognise as the decline factor towards the maintenance work in a heritage building. Some of the important factor that has been stated is due to certain obstacles like finance and allowance in the maintenance work. The work need high cost in the aspect of human resource and sources. Due to the obstacles, many owners will hang on the maintenance work rather than following the stated routine.

Another factor is due to the negative justification by certain bodies reasoning that the maintenance work will load to failure as compared to the benefits. This also imply from the development cite that needs space for development which later lead to demolish the building for a modern development that brings more benefit. Moreover, people nowadays no longer interested in visiting building that are gazetted and this made the owner feel that the effort in maintaining the building is worthless.

Besides that, mentality of certain people saying that maintenance is a low status profession as it involve with dirty and disgusting works. Hence, those works are put on the labourer's shoulders who do not have deeper knowledge and skill in maintaining a heritage building. As a result, the heritage building is not being maintained according to the procedure which later leads to major destruction. Moreover, there is no uniformity model or guideline for the owner to follow in maintaining their heritage building. This is the reason why maintaining work is not done base on the correct principle. However, all those factors should not be the cause or reason for not maintaining our heritage buildings. Effort in handling these factors are much needed to ensure our national assets can be inherited by our next generations.

\section{ON-GOING MAINTENANCE: ENCOURAGEMENT STRATEGY}

As a response to the decline factor, a few steps and strategies has been frame out to encourage the effort in maintaining until later it can become a continuously practice. At the same time, the owner of the building and those who involve in maintaining of the building can benefit effort done. As an early steps, researchers such as Brereton [6], Worthing et. al. [7]; Fieldan [2]; Dunn and Cantell [3] and Kayan [16] propose that a collaborative and consistent effort need to be enforce at the early administrative and excusive stage. This includes giving courses, hands on to those involve, workshops, seminars and certify to those who have the qualification.

Besides that, the policy and guidelines in maintaining and preserving the old building should be revised, so that the policy and guidelines would be more uniform. At the same time, a model of reference which consists of process of maintenance is also suggested to be developed. So, it can be referred by many parties. Aids and financial incentive should be given to those who are interested in developing the heritage sector including both maintaining and preserving of old building. At the lower stage, effort and support are needed in instilling the love for the national heritage at grass root level. Support should also be given to academician who involve in the process of maintaining and preserving the heritage building.

\section{CONCLUSIONS}

As referred to the above discussion, we can conclude that the practice of maintaining is a good step in protecting the heritage building from any harm that can slowed down the smoothness of the operation. A good maintenance come from a well planned execution as stated routinely from time to time via the on-going approach. Taking into consideration the age and condition of the heritage building. This approach is suitable because the remnants are very sensitive to deal with. If it is not being handled carefully, this national asset will lost from our sight one day. The effectiveness of the ongoing maintenance lies not only on the planning and execution but also from all sectors. This include from the government and non-government sectors, privates, individual and not to forget the publics. Contribution from all, had made what we inherit today can be everlasting for the next generation. Our Heritage, Our Future.

\section{ACKNOWLEDGMENT}

Highest acknowledgement to Universiti Tun Hussein Onn Malaysia (UTHM), fellow researcher and those who are involve direct or indirectly in the complement of this study.

\section{REFERENCES}

[1] Yahaya (1996), Some aspects of building conservation in Malaysia Pustaka Kajian Pemuliharaan Bangunan, Universiti Malaya.

[2] Fielden, B.M. (2003), Conservation of Historic Buildings, 3rd ed., archtectural Press, Oxford

[3] Dann, N and Cantell, T. (2005) Maintenance from philopsophy to practice, Journal of Architectural Conservation, Vol. 11 No. 1.

[4] Kayan (2003), Pengurusan penyenggaraan bangunan lama kerajaan, The Malaysian Surveyor, Vol 38.1, No. 1

[5] Hasnan A., (1994). Pengurusan Penyelenggaraan. Johor Bahru: Universiti Teknologi Malaysia (Terjemahan)

[6] Brereton (1995), The repair of Historic Buildings: Advice on Principles and Methods, English Heritage, London

[7] Worthin et. al., (2002), Issues in conservation management, Proceedings of the CIB w070 2002 Global Symposium: Applying and Extending the Global Knowledge Base, Glasgow.

[8] Keromo, P. (2006), Konservasi Secara Umum, Bengkel Konservasi Monumen dan Tapak Tanah Bersejarah, 27-29 November 2006, Hotel Mahkota, Melaka.

[9] International Council on Monuments and Sites (1999), The Burra Charter, International Council and on Monuments and Sites, Paris.

[10] Maintain Our Heritage (2004), Putting it off: How lack of Maintenance Fails our Heritage, Maintain our Heritage, Bath.

[11] Kayan (2009), Maintenance for historic buildings: a current perspective, Structural Survey, Vol 23 No. 3.

[12] Paul Wordswoth (2001), Lee's Building Maintenance Management 4th Edition. Blackwell Science

[13] Hakim dan Min (1991), Teknologi Penyenggaraan Bangunan, Kuala Lumpur

[14] Morris, W., 1887. The SPAB Manifesto, London. Society for the Protection of Ancient Buildings (SPAB)

[15] M.A.A. Rahman (2009), A Proposal on Developing Process Modeling for Maintenance Management of Heritage Building in Malaysia, ICON-BSE, 14 - 15 Disember 2009, Universiti Tun Hussein Onn Malaysia

[16] Kayan (2003), Pengurusan penyenggaraan bangunan lama kerajaan, The Malaysian Surveyor, Vol 38.1, No. 1 